\title{
JMSCR VoI||04||Issue||09||Page 12691-12698||September
}

www.jmscr.igmpublication.org

Impact Factor 5.244

Index Copernicus Value: 83.27

ISSN (e)-2347-176x ISSN (p) 2455-0450

crossref DOI: _http://dx.doi.org/10.18535/jmscr/v4i9.63

\author{
Journal Of Medical Science And Clinical Research \\ IGM Publication \\ An official Publication of IGM Publication
}

\section{Study of Prevalence of Various Cutaneous Manifestations Inchildren Suffering from Severe Acute Malnutrition (SAM)}

\author{
Authors \\ Dr Shruti Dhale ${ }^{1}$, Dr Muneshwar Bhongade ${ }^{2}$, Dr Sukena Susnerwala ${ }^{3}$ \\ ${ }^{1}$ Associate Professor, ${ }^{2,3}$ Resident \\ Dept of Paediatrics, Grant Govt. Medical College and Sir J.J Group of Hospitals Mumbai \\ Corresponding Author
}

Dr Muneshwar Bhongade

Resident, Dept of Paediatrics, Grant Govt. Medical College and Sir J.J Group of Hospitals Mumbai

\begin{abstract}
Aims and Objectives: To study prevalence of various cutaneous manifestations in children suffering from severe acute malnutrition (SAM) in the age group of 6 months to 5 years over a period of 6 months.

Study Design: It was prospective observational study done over a period of 6 months conducted at a tertiary care hospital. All patients between age group of 6months to 5 years who were diagnosed with severe acute malnutrition were enrolled in this study.

Materials and Methods: The study was approved by the Institutional ethical committee. The patients attending the Emergency, in-patient and outpatient Departments of Pediatrics Division of ourinstitute were enrolled for the study as per the criteria given. It was a prospective, observational study conducted on children in the age group of 6 months to 5 years having severe acute malnutrition. Clinical history, anthropometry, physical examination were carried out in details in all patients. The cutaneous manifestations present in these patients were studied in detail.

Results: The cutaneous manifestations were common in patients presenting with severe acute malnutrition. The Commonest manifestation was angular stomatitis/chelitis which was found to be present in 55\% cases. Other manifestation included pigmentary changes, bacterial infections, flaky paint dermatosis, fungal infections, crazy pavement appearance and flag sign were present in 30\%, 25\%,20\%,20\%,17.5\% and 15\% respectively. The less common features included ichthyosiform skin changes and acrodermatitis which were found in $10 \%$ and $5 \%$ of patients respectively.

Conclusion: Malnutrition affects almost all organ systems of body and skin is no exception to this. All patients presenting with or being treated for severe acute malnutrition should be throughly examined for any cutaneous lesion and if found it should be appropriately treated.

Keywords: Severe acute malnutrition, Cutaneous manifestation, cheilitis, acrodermatitis.
\end{abstract}

\section{Introduction}

The World Health Organization defines malnutrition as "the cellular imbalance between supply of nutrients and energy and the body's demand for them to ensure growth, maintenance, and specific functions." ${ }^{[1]}$ Severe Acute Malnutri- tion is defined as weight for height less than -3SD and/or visible severe wasting and/or edema of both feet (excluding other causes of edema), mid arm circumference less than $11.5 \mathrm{~cm}$ (in infant more than 6 months of age ${ }^{[2]}$. According to 
national family health survey III in India $6.4 \%$ of children below 5 years are suffering from severe acute malnutrition. The median case fatality rate is approximately $23.5 \%$. Malnutrition in children is rampant in developing countries and is responsible for more than half of the 10 million deaths annually among children less than 5 years. Over $2 / 3$ rd of these deaths which are often associated with inappropriate feeding practices occurred during 1 st year of life ${ }^{[3]}$.

While it can be seen in any age group children are most commonly affected by malnutrition and its complications. Malnutrition in women in child bearing age group adversely affect the infants and there is increase incidence of low birth weight babies in such women ${ }^{[4]}$. Malnutrition affects all organ systems of the body. Dietary protein is essential to provide amino acids for synthesis proteins, hormones and other compounds that have various vital roles. Energy is essential for almost all biochemical and physiologic functions in the body. Various micronutrient and macronutrient deficiencies which is usually seen in these patients adversely affect the normal physiological functioning of the body. Malnutrition is also responsible for decreased immunity and its consequences in the form of bacterial, viral and fungal infections. Various studies have shown that malnutrition affects cognitive and intellectual functions of the growing brain. In severe cases there is cerebral atrophy and other structural changes in brain. Various studies have also reported malnutrition to be causative factor in scholastic backwardness in school children $^{[5]}$. More recently, neuroimaging studies have found severe alterations in the dendritic spine apparatus of cortical neurons in infants with severe protein-calorie malnutrition. These changes are similar to those described in patients with mental retardation of different causes ${ }^{[6]}$.

Cutaneous manifestations are one of the most important manifestations of severe acute malnutrition. The etiology of these skin changes is multifactorial. It is very difficult to systematically describe their character purely in dermatological terms. The severity of skin lesions can predict the morbidity and mortality in patients admitted for malnutrition. Moreover skin lesions sometimes can point towards specific deficiencies like zinc deficiency in acrodermatitis or vitamin A deficiency in phernoderma. The proper clinical examination, systematic investigations and classification of skin lesions will improve the outcome of patients admitted with severe acute malnutrition $^{[7]}$

\section{Materials and Methods}

All study patients were enrolled at a tertiary care hospital in a metropolitan city of India. This tertiary care centre serves as a major referral centre for Maharashtra. It was a prospective, observational study conducted on children in the age group of 6 months to 5 years having severe acute malnutrition. The approval of ethical committee was obtained prior to conducting the study. All patients between age group of 6months to 5 years admitted in our hospital who met the criteria of SAM (weight for height less than -3SD and/or visible severe wasting and/or edema of both feet (excluding other causes of edema), mid arm circumference less than $11.5 \mathrm{~cm}$ )were enrolled in the study after the parents consented for study. Patients who are predisposed for cutaneous infections like those with immunodeficiency syndromes, HIV positive patients and children having primary skin disorders like epidermolysis, ichthyosis vulgaris, atopic dermatitis and eczema were excluded from the study. The demographic data like patient age, gender, address, provisional diagnosis date of admission and final diagnosis were noted. The nutritional history was noted down in detail. Other relevant history like antenatal, natal, postnatal, developmental, and immunisation history was also noted. Additionally, anthropometric measurements, including weight, presence of bilateral oedema, and mid-upper arm circumference, were recorded at the time of admission. Depending on a child's age and ability to stand, measurement of child's length or height was taken. The weighing of baby was done about one hour before or after a feed. A child's length was measured in lying 


\section{JMSCR Vol||04||Issue||09||Page 12691-12698||September}

down (recumbent) position. Height was measured with child standing upright position. Hemoglobin $(\mathrm{Hb} \%)$ was measured by Coulter method.

\section{Inclusion criteria:}

1) Age 6 months to 5 years.

2) Wt for Ht less than -3SD and/or Visible severe wasting and/or edema of both feet and/or mid arm circumference less than $11.5 \mathrm{~cm}$.

\section{Exclusion criteria:}

1) Children whose parents refused the consent to be part of the study.

2) Children less than 6 months of age

3) children more than 5 years of age

4) children with immunodeficiency

5) Patients having primary cutaneous disorders.

All patients enrolled in this study were examined for the cutaneous manifestations. The size, site and type of cutaneous manifestations were noted. The prevalence of these manifestations were studied in detail.

\section{Results}

Forty children aged between 6 months to 5 years meeting the defined criteria for severe acute malnutrition admitted in our hospital were enrolled in this study. Amongst the study group 22 were male and 18 were female. $\square$ Male

FEMALE

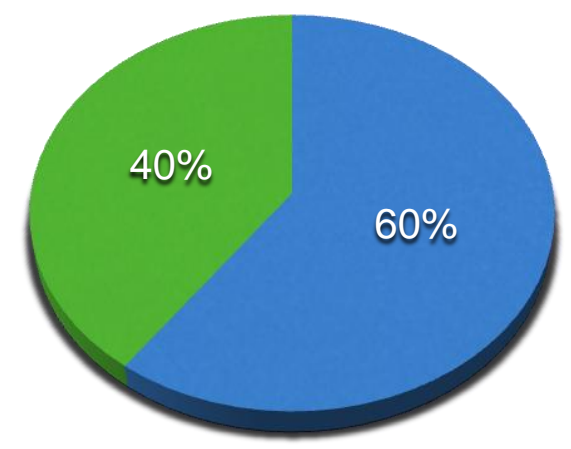

Fig 1: Gender of children having skin lesions in acute severe malnutrition.

Analysis of demographic data revealed that out of 40 children $26(65 \%)$ belonged to age group of $6 \mathrm{~m}-3$ years and 14 (35\%) belonged to age group between 3-6 years. Family history revealed that 22 (55\%) patients came from joint families while 18 $(45 \%)$ patients belonged to nuclear families. Immunization history of the patients revealed that $28(70 \%)$ patients were immunized up to date while $12(30 \%)$ patients were partially immunized. There was no patient who was totally un-immunized. Socioeconomically 12 (30\%) patients came from high/middle class while 28 (70\%) patients belonged to low socioeconomic families.

Table 1: Demographic data of cases

\begin{tabular}{|l|c|c|}
\hline Age & Number & Percentage \\
\hline 6 months- 3 years & 26 & $65 \%$ \\
\hline 3 years- 6 years & 14 & $35 \%$ \\
\hline Gender & & \\
\hline Male & 24 & $60 \%$ \\
\hline Female & 16 & $40 \%$ \\
\hline Family Type & & \\
\hline Joint Family & 22 & $60 \%$ \\
\hline Nuclear Family & 16 & $40 \%$ \\
\hline Immunisation status & & \\
\hline Up To Date & 28 & $70 \%$ \\
\hline Partially immunised & 12 & $30 \%$ \\
\hline Socioeconomic status & & \\
\hline High/ Middle class & 12 & $30 \%$ \\
\hline Low & 28 & $70 \%$ \\
\hline
\end{tabular}




\section{JMSCR VoI||04||Issue||09||Page 12691-12698||September}

An analysis of risk factors related to malnutrition revealed that child related risk factors were present in majority of cases. The study of these risk factors revealed that $8(20 \%)$ patients were low birth weight (birth weight less than $2.5 \mathrm{~kg}$ ). 24 patients $(60 \%)$ had one or more episodes of illness in last 2 months. The common illnesses were respiratory tract infections, diarrhea, viral illnesses like measles, chicken pox and mumps. In 10 patients $(25 \%)$ there was a history of an elder sibling with age difference of less than 2 years. 18 (45\%) patients belonged to high birth order. In 16 patients (40\%) dietary history could identify faulty dietary techniques like giving diluted milk, bottle feeding and delayed weaning etc.

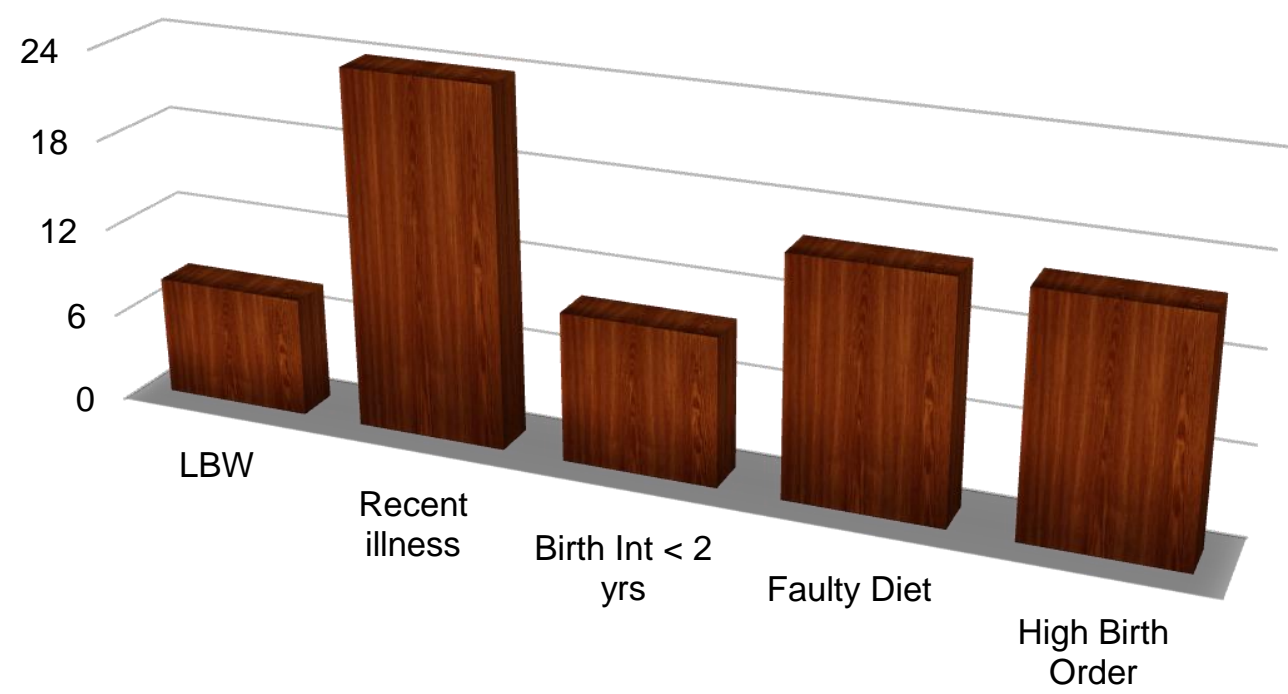

Fig 2: Child related risk factors for severe acute malnutrition.

\section{Maternal and Family Risk Factors}

There were many factors which were associated in malnutrition in children 6months to 5 years Socioeconomic-demographic factors like low socioeconomic status, residence in hilly areas etc were present in 10 patients (25\%), low maternal education was seen in 8 patients (20\%), poor knowledge of mother regarding proper feeding practice was present in 12 patients (30\%) Ignorance about continued feeding during sickness in children was present in mothers of 14 patients (35\%).

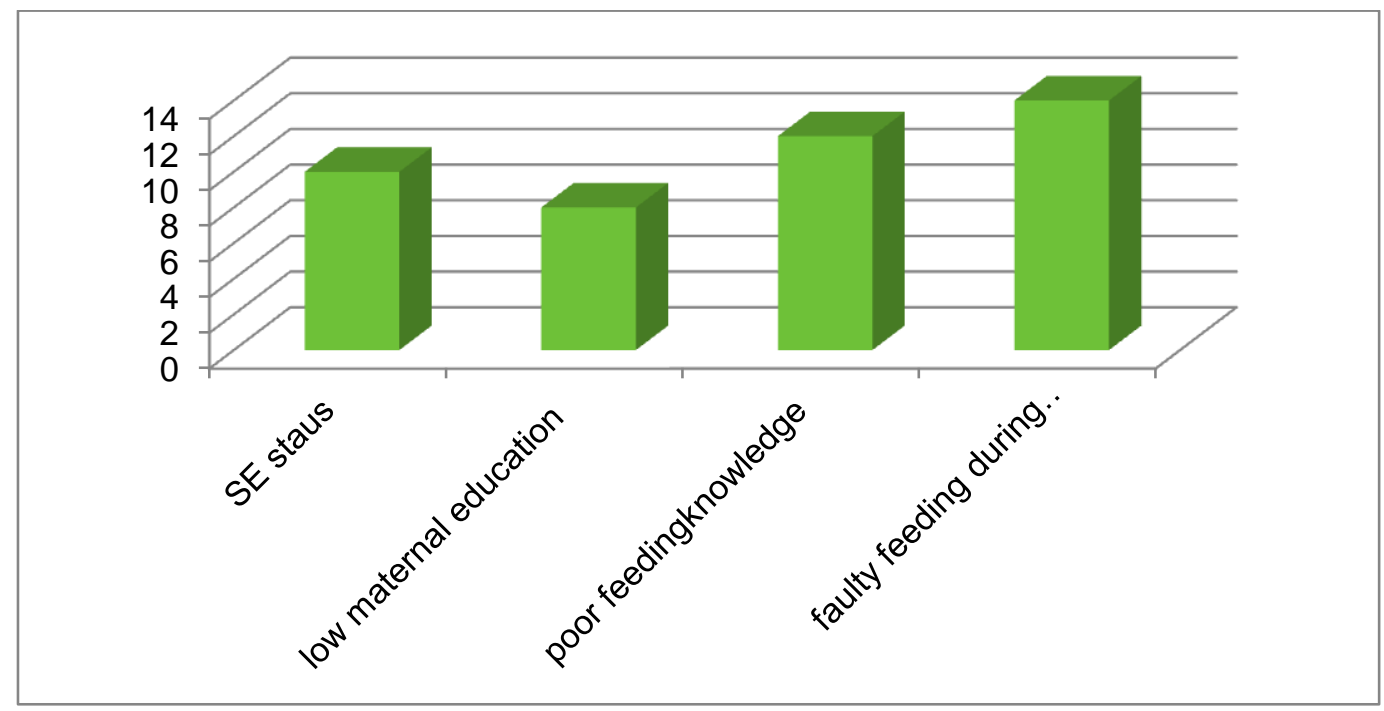

Fig 3: Maternal and family related risk factors for severe acute malnutrition. 


\section{JMSCR Vol||04||Issue||09||Page 12691-12698||September}

The clinical examination showed various vitamin and micronutrient deficiencies in children admitted with severe acute malnutrition. 6 patients (15\%) had signs of vitamin A deficiency in the form of xerophthalmia and other ophthalmological manifestations. While 22 patients $(55 \%)$ showed the signs of Vitamin B complex deficiency like cheilitis and stomatitis. Vitamin C deficiency signs in the form of bleeding gums was present in 2 patients $(5 \%)$. There are 2 patients $(5 \%)$ who showed some signs of vitamin D deficiency in the form of rickets. Signs of micronutrient deficiency was present in 12 (30\%) patients. Signs of iron deficiency in the form of pallor was present in 30 patients $(75 \%)$.

Table 2 : Signs of vitamin, micronutrient and iron deficiency in studied cases.

\begin{tabular}{|l|l|l|}
\hline Signs of deficiency & $\begin{array}{l}\text { No of } \\
\text { cases }\end{array}$ & Percentage \\
\hline Vitamin A & 6 & $15 \%$ \\
\hline Vitamin B Complex & 22 & $55 \%$ \\
\hline Vitamin C & 2 & $5 \%$ \\
\hline Vitamin D & 2 & $5 \%$ \\
\hline Micronutrient Deficiency & 12 & $30 \%$ \\
\hline Iron & 30 & $75 \%$ \\
\hline
\end{tabular}

On physical examination various physical signs related to malnutrition were observed. In 16 patients $(40 \%)$ there was edema and 24 patients $(60 \%)$ were non-edematous. Pallor was present in
30 patients $(75 \%)$ and hepatomegaly was present in 28 patients $(70 \%)$. Thin sparse hairs and perianal rash was present in $8(20 \%)$ and $12(30 \%)$ patients respectively.

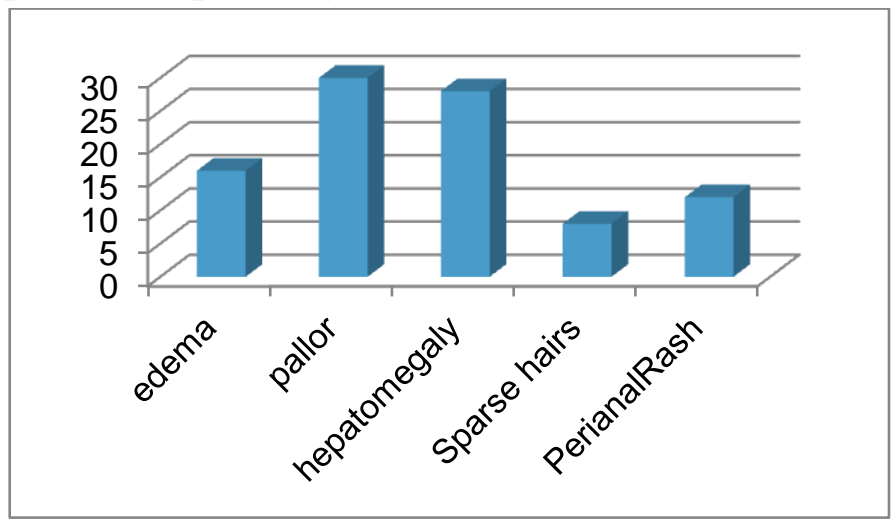

Fig 4: Signs present in children with severe acute malnutrition on physical examination.

All 40 patients of SAM were analysed after thorough clinical examination for cutaneous manifestations and the results are as follows. Angular stomatitis/cheilitis were found to be in $55 \%$ patients, pigmentary changes $30 \%$ patients, bacterial infections (impetigo, erysipelas, folliculitis) $25 \%$ patients, flaky paint dermatosis $20 \%$ patients, fungal infections (pityriasis, tinea, candida) $20 \%$ patients, crazy pavement appearance $17.5 \%$ patients, flag sign $15 \%$ patients, ichthyosiform skin changes $10 \%$ patients and acrodermatitis was found in $5 \%$ of patients.

Table 3 : Cutaneous manifestations in children suffering from severe acute malnutrition

\begin{tabular}{|l|l|c|c|c|c|}
\hline $\begin{array}{l}\text { Sr } \\
\text { no }\end{array}$ & Cutaneous manifestation & Male & Female & Total & Percentages \\
\hline $\mathbf{1}$ & Angular stomatitis / Cheilitis & 10 & 12 & 22 & $55 \%$ \\
\hline $\mathbf{2}$ & $\begin{array}{l}\text { Pigmentary Changes } \\
\text { (Hypopigmentations \& Hyperpigmentations) }\end{array}$ & 05 & 07 & 12 & $30 \%$ \\
\hline $\mathbf{3}$ & Bacterial Infections & 05 & 05 & 10 & $25 \%$ \\
\hline $\mathbf{4}$ & Flaky Paint Dermatosis & 03 & 05 & 08 & $20 \%$ \\
\hline $\mathbf{5}$ & Fungal & 04 & 04 & 08 & $20 \%$ \\
\hline $\mathbf{6}$ & Crazy Pavement Appearance & 03 & 04 & 07 & $17.5 \%$ \\
\hline $\mathbf{7}$ & Flag Sign & 03 & 03 & 06 & $15 \%$ \\
\hline $\mathbf{8}$ & Ichthyosiform Skin Changes & 02 & 02 & 04 & $10 \%$ \\
\hline $\mathbf{9}$ & Acrodermatitis & 01 & 01 & 02 & $5 \%$ \\
\hline
\end{tabular}




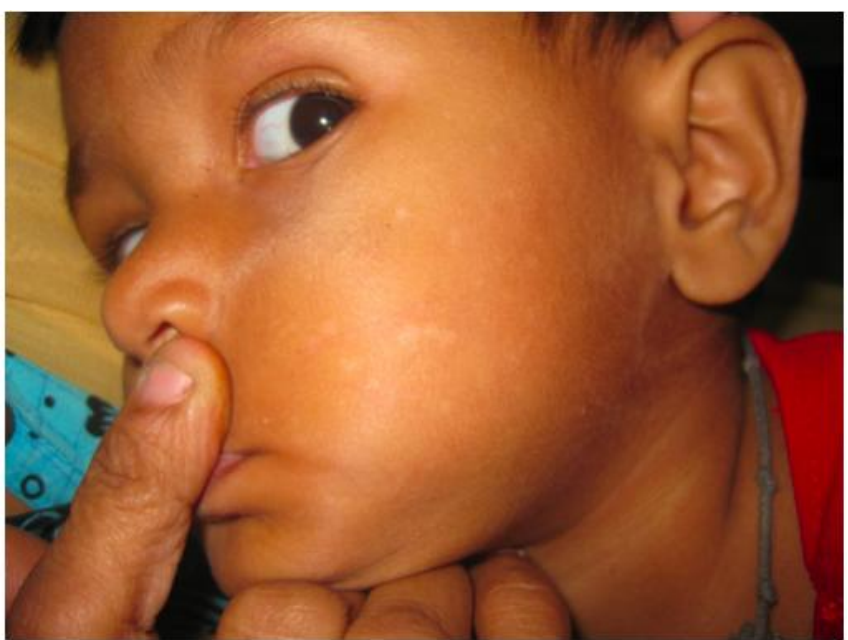

Figure 4: Pityriasis versicolor in a patient with severe acute malnutrition.

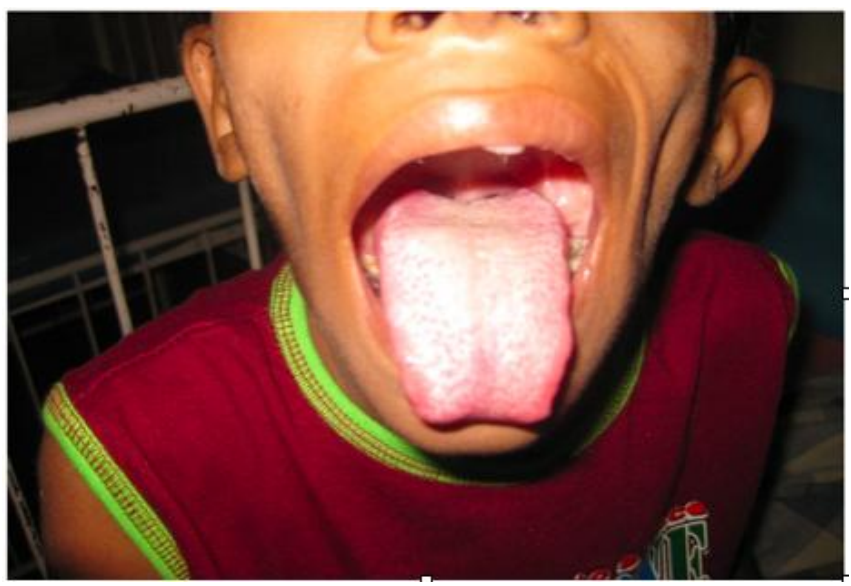

Figure 5: Oral candidiasis seen over the tongue in a patient with acute severe malnutrition.

Skin lesions were more common in areas subject to friction or pressure, for example the groin, knees, buttocks, ankles and at the elbows; in some patients the dermatosis was more extensive involving large parts of the body.

\section{Discussion}

Severe Acute Malnutrition is defined as weight for height less than -3SD and/or visible severe wasting and/or edema of both feet (excluding other causes of edema), mid arm circumference less than $11.5 \mathrm{~cm}$ (in infant more than 6 months of age). Clinical signs and symptoms of proteinenergy malnutrition (PEM) include Poor weight gain, short stature, behavioral problems, Irritability, decreased social interactions and response, attention deficit and hyperactivity. Some studies have even suggested that aggression; hyperactivity and conduct disorder may have its origin in malnutrition ${ }^{[8]}$. Malnutrition is one of the major challenges faced by developing world. Majority of the deaths in under 5 age group in developing countries are directly or indirectly related to the problem of malnutrition. The characteristics and etiological reasons are different for risk of malnutrition in developing and developed world. While Poor environmental conditions, high incidence of infections and infestations, reduced food production, poverty, food taboos and ignorance etc are major contributing factors in developing world ${ }^{[9]}$, in developed countries malnutrition is usually seen in children who are chronically ill or hospitalized ${ }^{[10]}$. There is a vicious circle in between poverty, ignorance and socioeconomic development and malnutrition. While low socioeconomic status, ignorance and poverty are major causes of malnutrition, malnutrition consequently causes increased poverty and further worsening of socioeconomic status of a community . Children suffering from malnutrition are also deficient in various vitamin and micronutrient deficiencies which causes widespread adverse effects and for this reason malnutrition is responsible for many of the indirect causes of under 5 mortality ${ }^{[11]}$.

Proper nutrition is essential for human bodies to work smoothly. Malnutrition affects adverse almost all organ system of the bodies. Proper nutrition is required for protein and amino acid synthesis. All biochemical, physiological and hormonal functions of the body are dependent upon a steady supply of nutrition through the food. Any imbalance in this may lead to severe dysfunction in the smooth functioning of the various systems of the body. Many of the nutrients acts as co-factors in many vital biochemical reactions are their deficiency will manifest in a widespread form if those micronutrients are deficient for any reason. Furthermore malnutrition affects immunity of an individual. This is more severely manifested in children specially infants as their immune system is still in the stage of maturation. decreased delayed hypersensitivity, reduced $\mathrm{T}$ lymphocytes, qualitative defects in $\mathrm{T}$ Lymphocyte functions, Impaired phagocytosis, 
and decreased surface immunity due to decreases IgA can occur ${ }^{[12]}$.

The presentation of severe acute malnutrition is weight for height less than -3SD and/or visible severe wasting and/or edema of both feet (excluding other causes of edema), mid arm circumference less than $11.5 \mathrm{~cm}$ (in infant more than 6 months of age). In addition to this patient may have widespread manifestations due to vitamin, micronutrient and macronutrient deficiencies. Physical findings of malnutrition include decrease subcutaneous fat in the legs, arms, buttocks, and face. Edema may be periorbital and localized initially but later gross edema leading to anasarca may develop. In addition to this sparse hairs, frontal bossing and other signs of rickets, abdominal distension due to lax abdominal muscle, hepatomegaly, brittle and ridged nails etc may be present ${ }^{[13]}$. Many skin lesions are seen in patients of severe acute malnutrition the skin lesions usually first occur in areas subject to friction or pressure, for example the groin, behind the knees, on the buttocks, and at the elbows; in advanced cases, the dermatosis may be almost anywhere on the body--trunk, limbs, or head. The common skin lesions seen in children with malnutrition are Angular stomatitis / Cheilitis, Pigmentary Changes, Bacterial Infections, Flaky Paint Dermatosis, Fungal infections, Crazy Pavement Appearance, Flag Sign, Ichthyosiform Skin Changes and Acrodermatitis $^{[14]}$. Proper management of severe acute malnutrition is essential to prevent morbidity and mortality Children with severe acute malnutrition with loss of appetite or any medical complication have complicated severe acute malnutrition and should be admitted for inpatient care. Children who have a good appetite and no medical complications can be managed as outpatients ${ }^{[15]}$. In hospital a quick initial assessment should be done for presence of hypoglycemia, infection, hypothermia, fever, dehydration or shock. If any evidence of these abnormalities is found then treatment should be immediately directed towards correction of these abnormalities ${ }^{[16]}$. After initial stabilization nutritional rehabilitation should be started. Patients should be kept in warm and thermo neutral environment. Micronutrient and macronutrient supplements should be given according to standard protocols. Nutritional rehabilitation in the form of ready-to-use therapeutic food (RUTF) and vitamin supplements is important in management ${ }^{[17]}$. Management of skin lesions seen in severe acute malnutrition is important. Neglecting skin lesion may cause superadded bacterial infections due to raw surface. Such infections are dangerous in a patient who already is immunocompromised due to malnutrition ${ }^{[18]}$. Many of the skin lesions will respond to nutritional rehabilitation and will improve as the child starts tolerating feeds but some of the skin lesions like acrodermatitis may require specific treatment like zinc supplementation ${ }^{[19]}$. The identification and management of such skin lesions in severe acute malnutrition is an essential part of management of children with $\mathrm{SAM}^{[20]}$.

\section{Conclusion}

Various skin lesions are seen in children with severe acute malnutrition. Proper examination of children to diagnose these skin lesions is essential part of management of SAM. Some of these skin lesions improve once nutritional rehabilitation is started while others need specific treatment.

\section{Conflict of Interest: None}

\section{References}

1. WHO. Malnutrition-The Global Picture. World Health Organization. Available at http://www.who.int/home-page/.

2. WHO-country office for India, NRHM. Facility based care of severe acute malnutrition. March 2011;10-11.

3. Soloman Amsalu, Zemene Tigabu. Risk factors for severe acute malnutrition in children under five, a case study. Ethiopia Journal of Health and Development.2008; 22(1):21-25. 
4. Blossner, Monika, de Onis, Mercedes. Malnutrition: quantifying the health impact atnational and local levels. 2005.

5. Leiva Plaza B, Inzunza Brito N, Pérez Torrejón H, Castro Gloor V, Jansana Medina JM, Toro Díaz T, Almagiá Flores A, Navarro Díaz A, Urrutia Cáceres MS, Cervilla Oltremari J, Ivanovic Marincovich D. [The impact of malnutrition on brain development, intelligence and school work performance]. Arch Latinoam Nutr. 2001 Mar;51(1):64-71. Review. Spanish.

6. Benitez-Bribiesca L, De la Rosa-Alvarez I, Mansilla-Olivares A. Dendritic spine pathology in infants with severe proteincalorie malnutrition. Pediatrics. 1999 Aug. 104(2):e21.

7. Heilskov S, Vestergaard C, Babirekere E, Ritz C, Namusoke H, Rytter M, Deleuran M. Characterization and scoring of skin changes in severe acute malnutrition in children between 6 months and 5 years of age. J Eur Acad Dermatol Venereol. 2015 Dec;29(12):2463-9

8. Liu J, Raine A. The effect of childhood malnutrition on externalising behavior. Curr Opin Pediatr. 2006 Oct;18(5):565-70. PubMed PMID: 16969174.

9. Heywood AH, Marshall T, Heywood PF. Motor development and nutritional status of young children in Madang, Papua New Guinea. P N G Med J. 1991 Jun. 34(2): 109-16

10. Hendricks KM, Duggan C, Gallagher L, et al. Malnutrition in hospitalized pediatric patients. Current prevalence. Arch Pediatr Adolesc Med. 1995 Oct. 149(10):1118-22.

11. Sahu SK, Kumar SG, Bhat BV, et al. Malnutrition among under-five children in India and strategies for control. Journal of Natural Science, Biology, and Medicine. 2015;6(1):18-23.

12. Rytter MJH, Kolte L, Briend A, Friis H, Christensen VB. The Immune System in Children with Malnutrition-A Systematic
Review. Akiyama T, ed. PLoS ONE. 2014;9(8):e105017.

13. Pocket Book of Hospital Care for Children: Guidelines for the Management of Common Childhood Illnesses. 2nd edition. Geneva: World Health Organization; 2013. 7, Severe acute malnutrition.

14. Gehrig KA, Dinulos JG. Acrodermatitis due to nutritional deficiency. Curr Opin Pediatr. 2010 Feb;22(1):107-12.

15. Collins S. Treating severe acute malnutrition seriously. Archives of Disease in Childhood. 2007;92(5):453-461.

16. Picot J, Hartwell D, Harris P, Mendes D, Clegg AJ, Takeda A. The effectiveness of interventions to treat severe acute malnutrition in young children: a systematic review. Health Technol Assess. 2012;16(19):1-316.

17. Scherbaum V, Fürst P. New concepts on nutritional management of severe malnutrition: the role of protein. Curr Opin Clin Nutr Metab Care. 2000 Jan;3(1):31-8.

18. Rodríguez L, Cervantes E, Ortiz R. Malnutrition and Gastrointestinal and Respiratory Infections in Children: A Public Health Problem. International Journal of Environmental Research and Public Health. 2011;8(4):1174-1205.

19. Lungarotti MS, Rufini S, Calabro A, Mariotti G, Ghebregzabher M, Monaldi B. Treatment of acrodermatitis enteropathica with zinc sulphate. Rerport of 3 cases. Helv Paediatr Acta. 1976 Aug;31(2):11720.

20. Hossain MI, Dodd NS, Ahmed T, et al. Experience in Managing Severe Malnutrition in a Government Tertiary Treatment Facility in Bangladesh. Journal of Health, Population, and Nutrition. 2009;27(1):7279. 